\title{
The friction of diamond-like carbon coatings in a water environment
}

\author{
D. C. SUTTON ${ }^{1, *}$, G. LIMBERT ${ }^{1,2}$, D. STEWART ${ }^{3}$, R. J. K. WOOD ${ }^{1}$ \\ ${ }^{l}$ National Centre for Advanced Tribology at Southampton (nCATS), Engineering Sciences, Faculty of Engineering and the Environment, \\ University of Southampton, Southampton, SO17 1BJ, UK \\ ${ }^{2}$ Bioengineering Science Research Group, Engineering Sciences, Faculty of Engineering and the Environment, University of Southampton, \\ Southampton, SO17 1BJ, UK \\ ${ }^{3}$ Materials, Chemistry and Corrosion, Rolls-Royce, Derby, DE21 7XX, UK \\ Received: 05 July 2013 / Revised: 07 August 2013 / Accepted: 12 August 2013 \\ (C) The author(s) 2013. This article is published with open access at Springerlink.com
}

\begin{abstract}
Diamond-like carbon (DLC) coatings are known to provide beneficial mechanical and tribological properties in harsh environments. Their combination of high wear resistance and low friction has led to their extensive use in any number of industries. The tribological performance of a DLC coating is varied however, and the frictional response is known to be strongly dependent on the surrounding environment, as well as the material composition and bonding structure of the DLC coating. This paper presents an up-to-date review on the friction of DLC coatings in a water environment, with a special focus on transfer layer formation and tribochemistry.
\end{abstract}

Keywords: friction; diamond-like carbon (DLC); water; transfer layer; tribochemistry; review

\section{Introduction}

Diamond-like carbon (DLC) coatings are of interest in a variety of applications to provide low wear and low friction. The main industry drivers for the development of DLC coatings relate to the potential for longer component lifetime, leading to cheaper components. Additionally, coated components are more energy efficient due to a reduction in frictional losses. Fundamentally, DLC coatings are comprised of carbon atoms bonded in an amorphous configuration; the proportion of $\mathrm{sp}^{3}$ and $\mathrm{sp}^{2}$ hybridisations of carbon in a DLC coating, the orientation and clustering of the $\mathrm{sp}^{2}$ phase, and the atomic structure of the carbon matrix, control the mechanical and tribological properties $[1,2]$. In addition, hydrogen is often present in the coating, either chemically bonded to the carbon matrix or trapped within interstitials. As a result of

* Corresponding author: D. C. SUTTON.

E-mail: ds6c10@soton.ac.uk this DLC coatings are termed hydrogenated or nonhydrogenated coatings.

The mechanical properties of a DLC coating are governed by a number of important factors. Fundamentally, the deposition method is a crucial factor in defining the mechanical response of a coating. An excellent review paper by Robertson [3] outlines the deposition methods, atomic structure, bulk properties, and mechanics of DLC coatings. A ternary phase diagram is often used to outline the various categorisations of DLC coatings. It was first presented by Jacob and Moller [4] for hydrogenated amorphous carbon (a-C:H) coatings and hydrogenated tetrahedral amorphous carbon (ta-C:H) coatings, and later was updated by Robertson [3] to include sputtered amorphous carbon (a-C) coatings, tetrahedral amorphous carbon (ta-C) coatings, and graphitic carbon coatings. The ternary phase diagram of Robertson [3] is shown in Fig. 1. The mechanical properties of each categorisation of DLC coating are given in Table 1 in terms of the 


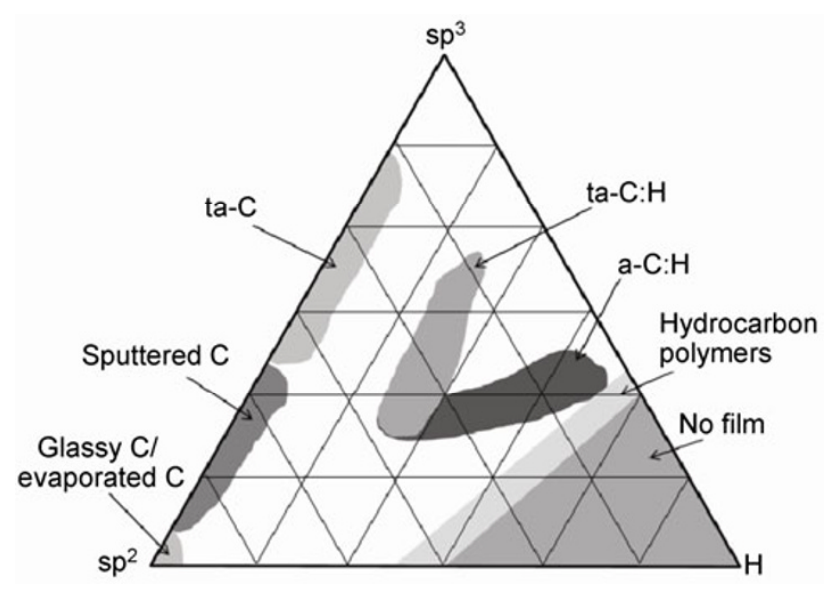

Fig. 1 The ternary phase diagram of DLC coatings $[3,10]$.

percentage of $\mathrm{sp}^{3}$ bonded carbon, the hydrogen content, approximate density, and typical hardness and Young's modulus.

The deposition of a DLC coating leads to intrinsic stresses in the carbon matrix. These stresses are known to vary as a function of the bias voltage $[5,6]$, power density [7, 8], and gas precursor [5]. Modern techniques allow for the deposition of multi-layer or gradient coatings, as well as doping or alloying of a DLC coating, and these are used to reduce internal stresses or to achieve some extra functionality. In this manner, DLC coatings can be tailored to application $[9,10]$.

A number of excellent review papers are available regarding the tribology of DLC coatings [12-17]. In particular, a book by Donnet and Erdemir [14] examines the tribology of DLC coatings in various environments. However, a review of the effects of a water environment on different types of DLC coatings under different test conditions is missing in the literature, and it is the aim of this paper to draw together an up-to-date representation of this. In addition, some recent work on the effects of the transfer layer on the tribology of DLC coatings in a water environment is included [18].

\section{Contributions to friction}

The friction of a DLC coating is dependent on a number of factors, relating to the composition of the DLC coating itself, and the interactions between the DLC coating and its surroundings. The deposition method, chemical composition, and roughness all strongly affect the coefficient of friction of a DLC coating. Additionally, the coefficient of friction is sensitive to the environment that the DLC coating slides in the counterface and the interfacial chemistry. Fontaine et al. [19] considers friction of DLC coatings to be a summation of adhesive, abrasive, and shear mechanisms. The magnitude of adhesive friction in a DLC coating is related to the coating microstructure, the environmental conditions, and the counterface. The strongest adhesive interactions in the context of DLC coatings are resultant from covalent bonds which form between the contacting surfaces, from the sigma orbitals of carbon atoms on the DLC surface. The presence of sigma orbitals may lead to high friction, but they may be passivated through reaction with environmental species or hydrogen present within the coating microstructure. An abrasive contribution to the friction of DLC coatings is due to mechanical interlocking of asperities, and is closely related to surface roughness of the coating. Thus abrasive interactions can be limited through deposition of a DLC coating onto a smooth substrate, since DLC coatings typically grow conformal to the substrate surface. Finally, DLC coatings are known to form a low shear strength layer of wear debris called a transfer

Table 1 An approximate categorisation of DLC coatings, and their mechanical properties [1, 3, 11].

\begin{tabular}{|c|c|c|c|c|c|}
\hline & $\mathrm{sp}^{3}(\%)$ & Hydrogen (\%) & Density $\left(\mathrm{g} / \mathrm{cm}^{3}\right)$ & Hardness (GPa) & Young's modulus (GPa) \\
\hline Graphite & 0 & 0 & 2.267 & $0.2-2$ & 10 \\
\hline Diamond & 100 & 0 & 3.515 & 100 & 1000 \\
\hline $\mathrm{a}-\mathrm{C}$ & $0-5$ & $<1 \%$ & $1.9-2.2$ & $10-20$ & $100-200$ \\
\hline a-C:H soft & 60 & $40-60$ & $1.2-1.6$ & $<10$ & $100-300$ \\
\hline $\mathrm{a}-\mathrm{C}: \mathrm{H}$ hard & 40 & $20-40$ & $1.6-2.2$ & $10-20$ & $100-300$ \\
\hline ta-C & $80-88$ & 0 & $3.1-3.3$ & $50-80$ & $300-500$ \\
\hline ta-C:H & 70 & 30 & 2.4 & 50 & 300 \\
\hline
\end{tabular}


layer [20-23]. The shearing component of friction accumulates from the energy required to cause plastic deformation to the transfer layer. The shear strength of this transfer layer has been shown to govern friction [24], and will vary with adsorption of environmental species such as water vapour.

\subsection{The effects of hydrogen}

The sensitivity of the coefficient of friction to the environment and the chemical composition of the DLC coating can be illustrated by considering the effects of hydrogen on the tribology of DLC coatings in dry and humid air. For non-hydrogenated coatings, the coefficient of friction in vacuum is often very large $(\mu>0.5)$ as a result of the strong adhesive forces between surfaces [25]. For hydrogenated coatings, the coefficient of friction in a vacuum is typically much less, with $\mu<0.001$ observed for highly hydrogenated a-C:H coatings deposited from methane at high ion energy [26]. Hydrogenated coatings have extremely low coefficients of friction in dry air, and in inert gases such as nitrogen [27]. The reason for this differing behaviour is related to the passivation of the surface of a DLC coating with hydrogen $[25,26]$. When a DLC coating contains hydrogen, or a DLC coating slides in a hydrogenated environment, hydrogen atoms bond to carbon atoms within the DLC coating, which limits the number of sites where covalent bonds can form between contacting surfaces, thus lowering adhesion. For non-hydrogenated coatings, this mechanism cannot occur since no hydrogen is present within the DLC coating microstructure, and therefore in a vacuum (or any inert environment) high adhesion is typically observed as a result of the reactivity of the DLC coating surface.

Erdemir [25] revealed a trend between the friction of DLC coatings and the source gas used during deposition. Coatings which were deposited with a higher ratio of hydrogen atoms to carbon atoms showed a lower coefficient of friction. This is due to a higher proportion of hydrogen terminated sigma bonds, minimising the number of adhesive interactions between surfaces.

Further complexity is observed when DLC coatings slide in reactive environments, for example in nitrogen with high humidity. In this environment, the sigma bonds on the surface of a non-hydrogenated DLC coating react readily with oxidative species, leading to fewer sites where adhesive interactions may occur and resulting in a reduction in the coefficient of friction. For hydrogenated DLC coatings in this environment, the polarity of oxygenated species present at the interface (adsorbed either physically or chemically) results in a higher coefficient of friction than that seen in an inert environment. For this reason the ultra-low coefficient of friction of $\mu<0.01$ observed in an inert environment is lost. Table 2 outlines the approximate range for the coefficient of friction in varying relative humidity $(\mathrm{RH})$ and in water for a-C, a-C:H, and ta-C coatings.

The tribochemical interactions that control the friction of hydrogenated coatings against a steel counterface were examined by Fontaine et al. [19, 32] by varying the partial pressure of hydrogen in a vacuum. The coefficient of friction was shown to be initially low (in the range 0.001-0.005) independent of the hydrogen partial pressure, but it increased suddenly to a coefficient of friction of 0.3 after some time. In tests with a higher hydrogen partial pressure, this increase in the coefficient of friction was further delayed. At 1,000 Pa partial pressure of hydrogen, this phenomenon was no longer observed. The initially low friction was linked to the internal store of hydrogen within the DLC coating. When this ran out, the

Table 2 An approximate range for the coefficient of friction in low relative humidity, high relative humidity, and in water, for a-C, $\mathrm{a}-\mathrm{C}: \mathrm{H}$, and ta-C coatings.

\begin{tabular}{cccc}
\hline \multicolumn{4}{c}{ Coefficient of Friction } \\
\hline & $<5 \% \mathrm{RH}$ & $5-100 \% \mathrm{RH}$ & Water \\
$\mathrm{a}-\mathrm{C}$ & $0.3-0.8[25,28]$ & $0.1-0.2[29]$ & $0.07-0.1[28]$ \\
$\mathrm{a}-\mathrm{C}: \mathrm{H}$ & $0.003-0.3[25,29,30]$ & $0.02-0.5[28,29,31]$ & $0.01-0.7[28]$ \\
ta-C & $0.4-0.8[27,29]$ & $0.08-0.12[21,28]$ & $0.07[27]$ \\
\hline
\end{tabular}


low friction could only be maintained from slidinginduced reaction of the DLC surface and the hydrogen within the environment. The sudden increase in friction was linked to the failure to replenish the surface of the DLC coating with hydrogen, resulting in adhesive interactions between surfaces.

The sliding velocity has been shown to affect the dynamic friction of a hydrogenated DLC coating sliding against itself [33]. As the velocity increased, the coefficient of friction was observed to decrease non-linearly (see Fig. 2). This can be explained in terms of adhesive interactions on a molecular level where a small sliding velocity provides time for many adhesive bonds to form due to an asperity contact, causing a large frictional resistance, whereas an large sliding speed will limit the number of bonds that have time to form between surfaces, causing a reduction in the coefficient of friction.

On a similar note, the dependence of the coefficient of friction on the dwell time in humid air was investigated by Heimberg et al. [33], showing that the longer that the DLC coating is left in humid air, the greater the increase in the coefficient of friction (when sliding against itself). This can be attributed to the adsorption of oxygen and other reactive species onto the surface of the DLC coating, displacing the hydrogen from the surface and increasing the polarity of the surface. This time dependent behaviour led to higher adhesive friction for longer dwell time.

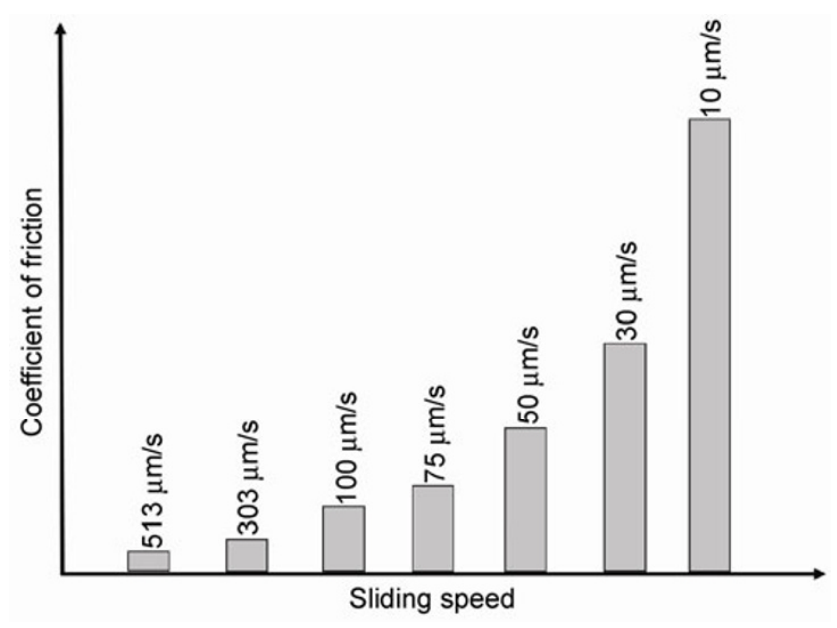

Fig. 2 The effect of sliding speed on the coefficient of friction of hydrogenated DLC coatings, reproduced from [33].

\subsection{The effects of doping and alloying}

The inclusion of metal or non-metal dopants or interlayers within a DLC coating microstructure will affect the frictional response $[9,13]$. The tribology of Si doped a-C:H coatings against steel in ambient air was investigated first by Oguri et al. [34] in sliding wear tests of $10-50 \mathrm{~N}$ load and $0.2-3 \mathrm{~m} / \mathrm{s}$ velocity. A low coefficient of friction of 0.04 was observed, contrary to a coefficient of friction of 0.12 for undoped coatings. Gilmore et al. [35] examined a range of commercial and in-house DLC coatings with varying Si content, and found a reduction in the coefficient of friction of Si doped coatings in high humidity against both steel and DLC counterfaces. Rubio-Roy et al. [36] showed a decrease in the coefficient of friction of $\mathrm{F}$ doped DLC coatings against tungsten carbide balls as relative humidity increased from $20 \%$ to $60 \%$. It is evident that the correct addition of a dopant can improve the properties of a DLC coating without sacrificing the wear resistance associated with these coatings.

\subsection{Transfer layer formation}

The formation of a low shear strength layer termed a transfer layer is well known for DLC coatings. A transfer layer is typically composed of disordered carbon wear debris from the DLC coating, as well as wear debris from the counterface, and any reactive environmental species. This third-body governs the frictional response by controlling the adhesive interactions that can occur between surfaces. The adherence of the transfer layer depends on the counterface material as well as the test environment. Investigations into the tribology of DLC coatings show that the formation of a transfer layer is common [20, 21, 37-39]. The concept of transfer layer formation has been reported since the advent of DLC coatings [40] and has been linked to a decrease in the coefficient of friction [31]. Transfer layers appear thicker with increased sliding velocity and normal load [28], and can develop in ambient air as well as in a humid atmosphere [27], or in water [41].

It has been discussed that the formation of a transfer layer is beneficial, but the conditions under which a transfer layer will develop are unknown, and are sensitive to test parameters. Scharf and Singer 
[22, 42-44] investigate the mechanisms by which transfer layers form for a range of commercial DLC coatings using in situ Raman spectroscopy and optical microscopy to demonstrate how third-body processes govern the frictional behaviour. The dynamics of a transfer layer are discussed in two distinct ways, and are defined as the velocity accommodation modes (VAMs) of the third body. The velocity accommodation modes are described below, and depicted in Fig. 3.

- Shearing and extrusion of debris (see Fig. 3(a)); detached wear particles from a DLC coating may loosely shear between two surfaces. Many sit in the valleys between surfaces causing surface smoothing by valley in-fill, or are lost from the contact region entirely. This may lead to further contact between surfaces increasing two body wear.

- Interfacial sliding (see Fig.3(b)); wear particles from a DLC coating may adhere to the counterface. This static transfer layer prevents two body wear between surfaces and acts as a sacrificial layer.

In any contact, both processes are likely to occur simultaneously in local regions. The formation of a static transfer layer through interfacial sliding will depend on the local contact pressure and temperature distribution, as well as third body chemistry.

In the work of Scharf and Singer [22, 42-44], the formation of a transfer layer was examined during reciprocating sliding tests of a sapphire ball against the DLC coatings in dry $(<5 \%$ relative humidity) air. An initially high coefficient of friction of 0.25 dropped rapidly to 0.05 and remained constant for the next 300 cycles. The in situ optical images showed how a transfer layer developed and remained static on the ball surface. The VAM was interfacial sliding between surfaces. Raman spectra showed development of the D-peak as the test continued, indicating graphitic material at the interface, due to graphitisation of the DLC coating. Later in the test, a spike in the coefficient of friction occurred before returning again to steady-state behaviour. The Raman spectra showed a decrease in intensity of the D-peak in the cycles previous, suggesting that the transfer layer was wearing from the region. Optical microscopy showed the loss of some of the transfer layer, which was the reason for the observed increase in the coefficient of friction. The subsequent return to low friction was due to shear and extrusion of debris, which continued until the transfer layer had healed (either from reattachment of loose debris or from further wear of the DLC coating) and interfacial sliding resumed.

The importance of the development of a transfer layer on the friction of DLC coatings is clear. The velocity accommodation mode is affected by the composition of the DLC coating, and is expected to vary as a function of test parameters, such as load and sliding velocity, and service conditions. Importantly, the formation of a transfer layer is dependent on the test or service environment, and therefore we

(a) Shear and extrusion of loose debris

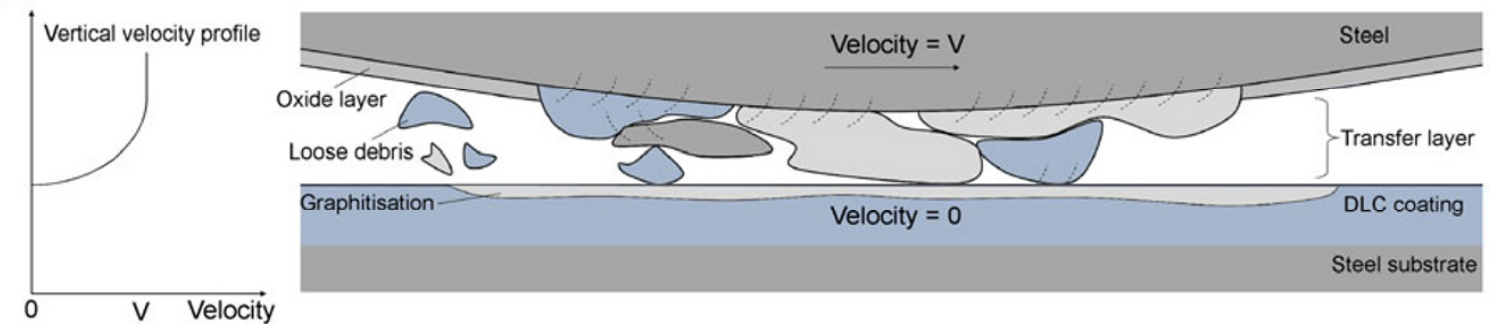

(b) Interfacial sliding

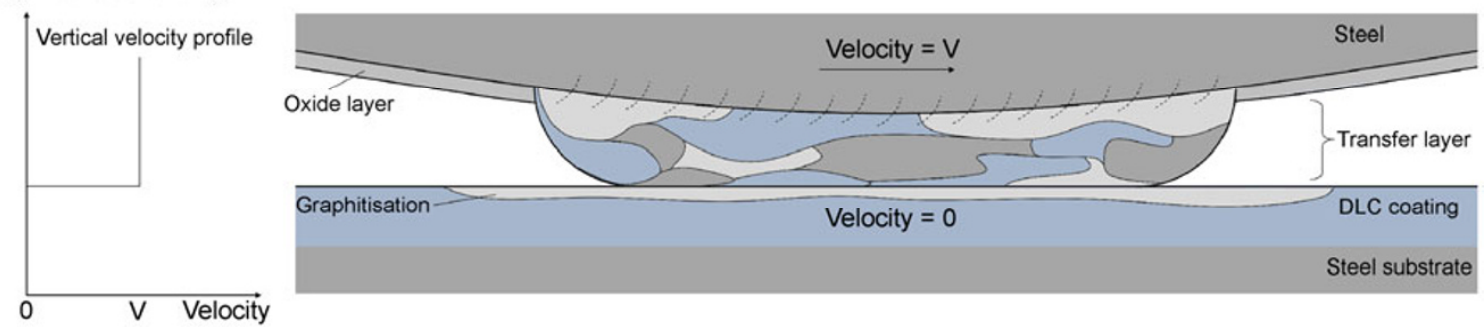

Fig. 3 The velocity accommodation modes of a transfer layer; (a) shear and extrusion of debris, and (b) interfacial sliding, based on Refs. [43, 44]. 
now focus on the friction of DLC coatings in a water environment, to examine the potential for the use of DLC coatings on components under aqueous lubrication.

\section{Friction in a water environment}

The friction of a DLC coating under water lubrication will vary as a result of the deposition process, but will also vary as a function of test parameters such as normal load and sliding velocity. The mechanical motions of the third-body will have a strong influence on friction, as will the tribochemistry. This section attempts to capture the current state of the literature, and the various contributions to friction of a DLC coating under water lubrication.

When a hydrogenated DLC coating slides in distilled water, the low friction that is present in an inert environment is disturbed. The hydrogen passivation mechanism of Erdemir [25,26] is replaced by the preferential adsorption of the most polar molecules onto the DLC surface [45], and as a consequence the friction is controlled by the molecular species at the interface as opposed to the hydrogen content of the coating. In addition, a non-hydrogenated DLC coating that shows a high coefficient of friction in an inert environment may provide a similar coefficient of friction to that of a hydrogenated coating in water [46]. Table 2 outlined the approximate range for the coefficient of friction in varying humidity and in water for a-C, a-C:H, and ta-C coatings.

Ronkainen et al. [41] investigated a range of hydrogenated and non-hydrogenated DLC coatings in reciprocating sliding against alumina balls at a $5 \mathrm{~N}$ load and $0.004 \mathrm{~m} / \mathrm{s}$ sliding velocity. Table 3 shows a summary of their results for the range of commercially deposited DLC coatings. The plasma-enhanced chemical vapour deposition (PECVD) coatings failed within the first $100 \mathrm{~m}$, whereas non-hydrogenated pulsed vacuum arc coatings showed a low coefficient of friction (0.04-0.05). The pulsed vacuum arc coatings showed a high coefficient of friction initially which reduced throughout the tests. No chemical analysis was performed but this reduction in friction was most likely to the development of a transfer layer. In addition, the authors suggest that hydrogenated coatings are susceptible to a higher specific wear rate in water, but that this can be remedied with the use of dopants and/or multilayers. The tribology of pulsed laser deposited DLC coatings against steel balls in humid air was also examined by Voevodin et al. [31]. A decreasing coefficient of friction was observed with increased relative humidity, and was lowest for nonhydrogenated ta-C coatings $(\mu \simeq 0.07)$.

Ronkainen and Holmberg [28] report the effects of load and sliding velocity on the frictional performance of ta-C coatings sliding against steel in $50 \% \mathrm{RH}$. The coefficient of friction varied over the range 0.14-0.19 as a function of sliding velocity and normal load. The highest load $(35 \mathrm{~N})$ and highest sliding velocity $(2.6 \mathrm{~m} / \mathrm{s})$ led to the highest coefficient of friction $(\mu=0.23)$.

The effects of test parameters were also explored by Uchidate et al. [47] who studied the tribology of a magnetron sputtered DLC coating versus stainless

Table 3 The mechanical properties and tribological results of 7 commercially produced DLC coatings in a water environment at room temperature [41].

\begin{tabular}{|c|c|c|c|c|c|}
\hline Coating & Deposition method & $\begin{array}{l}\text { Hydrogen } \\
\text { content }\end{array}$ & Friction coefficient & $\begin{array}{c}\text { Wear rate } \\
\left(\times 10^{-6} \mathrm{~mm}^{3} / \mathrm{Nm}\right)\end{array}$ & Transfer layer \\
\hline $\mathrm{a}-\mathrm{C}: \mathrm{H}$ & PECVD & $25-40 \%$ & 0.05 & Coating wore through & Yes \\
\hline $\mathrm{a}-\mathrm{C}: \mathrm{H} / \mathrm{Si}$ & PECVD & $\approx 30 \%$ & 0.06 & 0.2 & No \\
\hline $\mathrm{a}-\mathrm{C}: \mathrm{H} / \mathrm{W}$ & Magnetron sputtering & $\approx 10 \%$ & 0.08 & 0.3 & Yes \\
\hline $\mathrm{a}-\mathrm{C} / \mathrm{Cr}$ & Magnetron sputtering & $\approx 0 \%$ & 0.12 & 2 & Yes \\
\hline $\mathrm{a}-\mathrm{C}: \mathrm{H} / \mathrm{Si}$ & Ion beam & $\approx 10 \%$ & 0.07 & 0.2 & Yes \\
\hline ta-C & $\begin{array}{c}\text { Pulsed vacuum arc } \\
\text { discharge }\end{array}$ & $\approx 0 \%$ & 0.03 & Immeasurable & No \\
\hline $\mathrm{a}-\mathrm{C}$ & $\begin{array}{c}\text { Pulsed vacuum arc } \\
\text { discharge }\end{array}$ & $\approx 0 \%$ & 0.04 & Immeasurable & No \\
\hline
\end{tabular}


steel in distilled water in a ball-on-disc setup, to examine the potential for DLC coatings to be used in nuclear applications. Using an autoclave they varied the dissolved oxygen concentration, pressure, temperature, and load. Figure 4 shows the experimental findings extracted using an experimental design statistical method. The coefficient of friction was higher in quasi-tap water in all tests, and is much larger at $80^{\circ} \mathrm{C}$. Analysis of ball wear scars showed that a relatively thick $(500 \mathrm{~nm})$ transfer layer formed at $20{ }^{\circ} \mathrm{C}$, which thinned to a few $\mathrm{nm}$ at $80^{\circ} \mathrm{C}$, as identified by Auger electron spectroscopy (AES) depth profiling. Chemical mapping showed the transfer layer consisted of mostly Fe, C, and O. The increased friction at high temperature can be linked to the degradation of the transfer layer, as can be seen by the images in Fig. 5.

Recently, the consequence of surface texturing on the coefficient of friction of a DLC coating was considered by Ding et al. [48] for magnetron sputtered coatings under water lubrication. Grooves of 3-4 $\mu \mathrm{m}$ depth and $40 \mu \mathrm{m}$ width were spaced at various distances along the surface, before the steel substrate was coated. Grooves lay perpendicular to the sliding direction. An optimal distance was found between grooves to provide a lower coefficient of friction

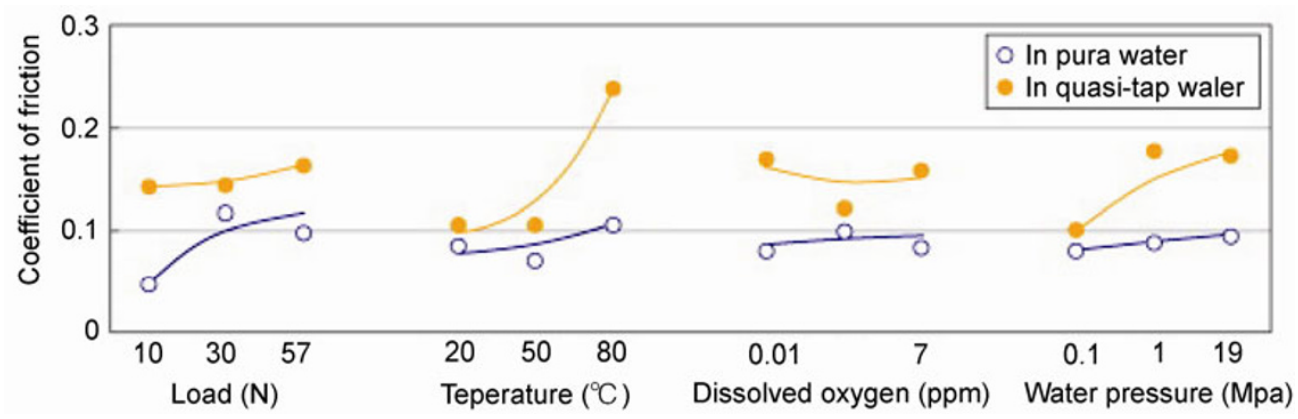

Fig. 4 The effects of load, temperature, dissolved oxygen, and water pressure, on the coefficient of friction, in the case of pure deionised water and quasi-tap water [47].

(a) Overview $\left(20^{\circ} \mathrm{C}\right)$

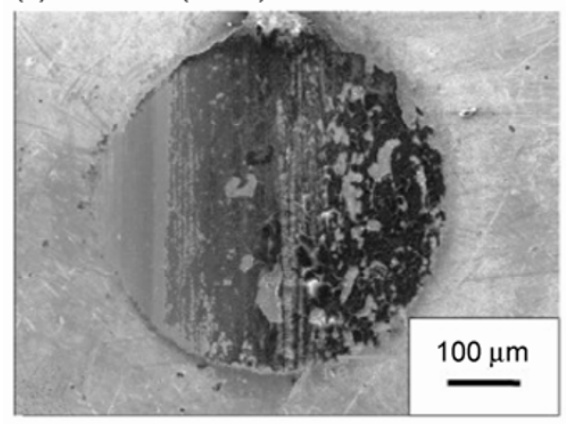

(c) $20^{\circ} \mathrm{C}$

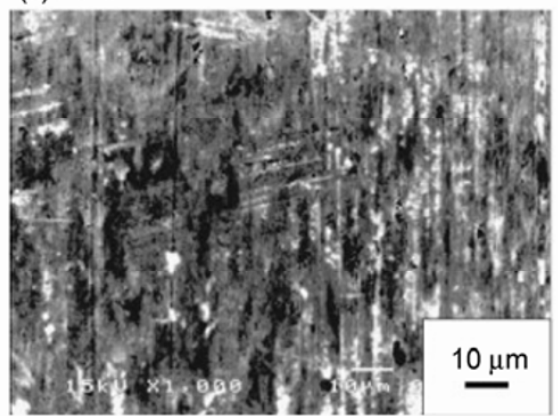

(b) $20^{\circ} \mathrm{C}$

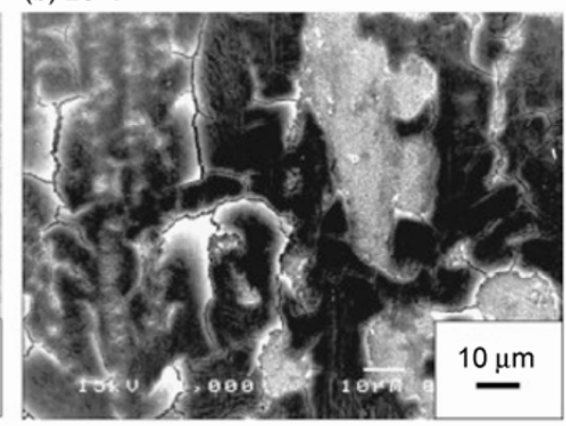

(d) $80^{\circ} \mathrm{C}$

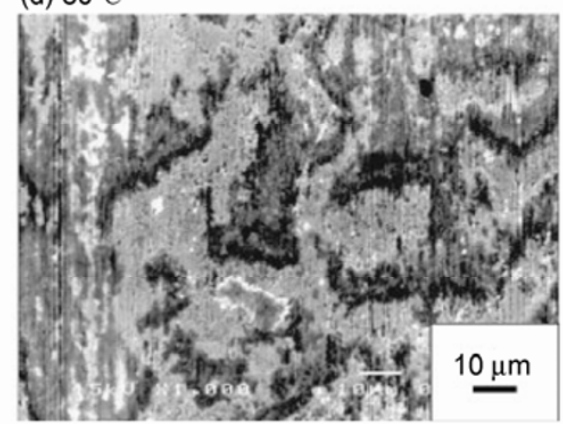

Fig. 5 SEM images of transfer layers formed at (a-b) $20{ }^{\circ} \mathrm{C}$, (c) $50{ }^{\circ} \mathrm{C}$, and (d) $80{ }^{\circ} \mathrm{C}$, in quasi-tap water at a $57 \mathrm{~N}$ load against stainless steel [47]. 
than the untextured surface. In another study, surface polishing of DLC coatings by aero-lapping and diamond slurry were compared to as-deposited magnetron sputtered coatings [49]. Under water lubrication, the aero-lapped DLC coating showed the lowest and most stable coefficient of friction but high wear comparative to the as-deposited DLC coating. The diamond slurry polished coating showed a reduced friction value and the lowest wear volume.

The effect of the third body on the friction of DLC coatings under water lubrication was examined recently by Sutton et al. [18], who have linked the tribological response of a selection of commercial DLC coatings with the formation of transfer layers. Optimum tribological behaviour was observed when the VAM was interfacial sliding, where a low and steady coefficient of friction was observed. Alternatively, shear and loss of the transfer layer led to a high and erratic coefficient of friction. In the case of shear, Raman spectra showed loss of the carbonaceous transfer layer as wear tests continued-leading to third-body abrasive wear involving iron oxide particles. The importance of the third-body on the tribology of DLC coatings is clear, and the formation of a carbonaceous transfer layer is known to lead to a low and steady coefficient of friction-however the conditions under which a stable transfer layer will form are unknown, and further investigations are needed to understand the conditions under which a stable transfer layer will develop.

\subsection{Tribochemistry of DLC coatings}

In order to understand the mechanisms behind the friction of DLC coatings under water lubrication, much effort has gone into understanding the changes in tribochemistry and their effect on friction. In particular it should be noted that the counterface plays an important role here. Previously, Park et al. [50] have focused their efforts on the tribochemistry of hydrogenated PECVD coatings sliding against steel in humid air. With increasing humidity, the coefficient of friction increased in value from 0.025 (at $0 \%$ humidity) to 0.2 (at $90 \%$ humidity). Analysis of the worn surfaces showed an increase in the size of $\mathrm{Fe}$ rich debris with increasing humidity, suggesting that the high friction observed is a result of tribochemical reactions between the steel ball and the DLC coating, and not an inherent tribological property of the DLC coatings.

Additionally, Li et al. [51,52] investigated the tribochemistry of hydrogenated DLC coatings tested in a $100 \% \mathrm{RH}$ nitrogen environment against a range of counterface materials. Against a steel ball, the coefficient of friction increased gradually from 0.05 to 0.2 over the duration of the test. Comparative friction traces for silicon nitride and aluminium oxide balls against a DLC coating showed steady behaviour in comparison. The reason for this differing behaviour was suggested to be due to tribochemical reactions between the steel ball and the DLC coating. In further work, identical DLC coatings were tested against steel balls in a nitrogen environment at different relative humidity [51]. The coefficient of friction varied from 0.05 to 0.20 with increased relative humidity. A compact transfer layer was present on the steel counterface at low $\mathrm{RH}$, whereas the formation of a carbonaceous transfer layer was suppressed at a higher RH. X-ray photoelectron spectroscopy (XPS) showed that at a higher $\mathrm{RH}$, the increased coefficient of friction was due to oxidation of the DLC coating and chemical reactions between the DLC coating, steel ball, and water and oxygen molecules present. Specifically, at $<5 \% \mathrm{RH}$, the presence of $\mathrm{C}-\mathrm{C}, \mathrm{C}-\mathrm{H}, \mathrm{C}-\mathrm{O}$, and $\mathrm{C}=\mathrm{O}$ bonding on the $\mathrm{C} 1 \mathrm{~s}$ spectrum was detected. As humidity increases, the formation of $\mathrm{O}-\mathrm{C}=\mathrm{O}$ bonding was observed, as well as a reduction in the proportion of $\mathrm{C}-\mathrm{C}$ and $\mathrm{C}-\mathrm{H}$ bonding. At $100 \% \mathrm{RH}, \mathrm{Fe}-\mathrm{C}$ was observed, suggesting tribochemical reactions occurred directly between the DLC coating and steel ball. Observation of the $\mathrm{O} 1 \mathrm{~s}$ state showed the presence of $\mathrm{Fe}-\mathrm{O}$ bonds, suggesting the formation of $\mathrm{Fe}_{2} \mathrm{O}_{3}$, $\mathrm{Fe}_{3} \mathrm{O}_{4}$, and $\mathrm{FeOOH}$.

For DLC coatings sliding against steel in humid conditions, Li et al. [51,52] proposed the following reaction mechanism (Fig.6); mechanical cracking to the DLC surface occurs during sliding as a result of shear forces, breaking $\mathrm{C}-\mathrm{C}$ and $\mathrm{C}-\mathrm{H}$ bonds and producing macro-radicals which may react with the environment. In the presence of water or oxygen molecules, peroxide radicals could result in the formation of hydro-peroxide groups on the DLC surface $(-\mathrm{COOH})$, as well as $\mathrm{C}-\mathrm{O}$ and $\mathrm{C}=\mathrm{O}$ functional groups. Against steel, activated $\mathrm{Fe}$ atoms could also form $\mathrm{Fe}-\mathrm{C}$ bonds. 


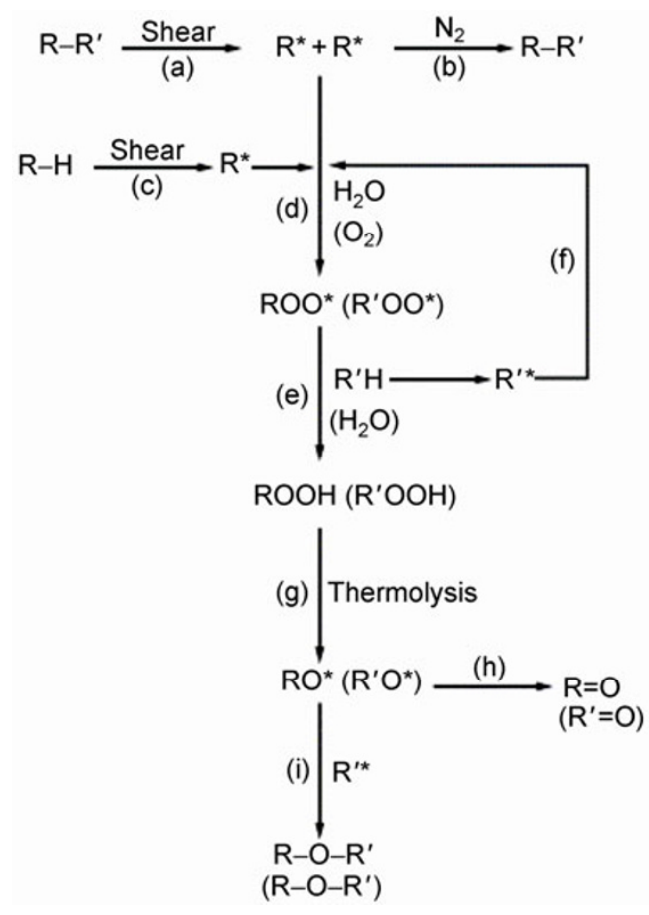

Fig. 6 A proposed reaction mechanism for the cracking and oxidation of DLC coatings in humid environments [51, 52].

The friction of DLC coatings sliding in a humid environment can then be linked to tribochemical reactions between surfaces, and oxidation of the DLC coating surface. Since the root of adhesion in a DLC coating is the formation and breaking of bonds, it has been suggested that the increase in the coefficient of friction in the presence of humidity is related to an increase in the average bond strength from $0.08 \mathrm{eV}$ per bond for hydrocarbons, to $0.21 \mathrm{eV}$ per hydrogen bond at $\mathrm{C}-\mathrm{O}$ and $\mathrm{C}=\mathrm{O}$ sites [28]. Against steel, a high and erratic coefficient of friction is observed, and is due to the formation and breaking of $\mathrm{Fe}-\mathrm{C}$ bonds, which leads to strong adhesion between the surfaces. Liu et al. [53] suggested that the reaction of iron with water could occur at $100-300{ }^{\circ} \mathrm{C}$, resulting in the following reactions.

$$
\begin{aligned}
& 2 \mathrm{Fe}+6 \mathrm{H}_{2} \mathrm{O} \longrightarrow 2 \mathrm{Fe}(\mathrm{OH})_{3}+3 \mathrm{H}_{2} \\
& 4 \mathrm{Fe}+3 \mathrm{O}_{2}+6 \mathrm{H}_{2} \mathrm{O} \longrightarrow 4 \mathrm{Fe}(\mathrm{OH})_{3}
\end{aligned}
$$

Since $\mathrm{Fe}(\mathrm{OH})_{3}$ is easily oxidised, the formation of $\mathrm{Fe}_{2} \mathrm{O}_{3}, \mathrm{Fe}_{3} \mathrm{O}_{4}$, and $\mathrm{FeOOH}$ could occur. Previously, the presence of magnetite $\left(\mathrm{Fe}_{3} \mathrm{O}_{4}\right)$ during the oxidation of steels in water has been linked to higher speeds and temperatures than hematite $\left(\alpha-\mathrm{Fe}_{2} \mathrm{O}_{3}\right)$ [54]. Also, the transition of magnetite to maghemite $\left(\gamma-\mathrm{Fe}_{2} \mathrm{O}_{3}\right)$ to hematite is well established under sufficiently high temperature or pressure [55] (see the reaction below).

$$
\mathrm{Fe}_{3} \mathrm{O}_{4} \stackrel{200^{\circ} \mathrm{C}}{\longrightarrow} \gamma-\mathrm{Fe}_{2} \mathrm{O}_{3} \stackrel{400^{\circ} \mathrm{C}}{\longrightarrow} \alpha-\mathrm{Fe}_{2} \mathrm{O}_{3}
$$

In a water environment, Wu et al. [56] studied the tribology of a DLC coating sliding against $440 \mathrm{C}$ steel using a stable isotopic tracer $\left(\mathrm{H}_{2}{ }^{18} \mathrm{O}\right)$ in order to investigate the influence of water in tribochemical reactions at the interface. The coefficient of friction decreased from a high initial value to a steady state around 0.06. Time of flight secondary ion mass spectroscopy (TOF-SIMS) was used to analyse the surfaces inside the wear track, and on the transfer layer. In $\mathrm{H}_{2}{ }^{18} \mathrm{O}$, the spectra showed two peaks at 18.00 and 19.01 atomic mass unit (amu) which were absent in the spectra taken outside the wear track. These peaks were assigned to ${ }^{18} \mathrm{O}^{2-}$ and ${ }^{18} \mathrm{OH}^{-}$respectively, suggesting tribochemical reactions occurred directly between the DLC wear scar and the water. TOF-SIMS analysis of the transfer layer formed on the steel ball showed evidence of ${ }^{18} \mathrm{O}$ and ${ }^{18} \mathrm{OH}$ in greater concentration than $\mathrm{O}$ and $\mathrm{OH}$, suggesting that the initial oxide layer on the ball was lost, and that tribochemical reactions with water occurred. Wu et al. [56] suggest that low friction in water is related to the formation of hydrophilic groups on the contact surfaces, such as hydroxyl and carboxyl functional groups on the DLC coating wear scar, and hydroxyl groups on the counterface surface, that they observed in their TOF-SIMS analysis. They postulate that the presence of hydrophilic groups will lead to a surface layer rich in water, preventing adhesion between surfaces.

It is clear from the above that when a DLC coating slides against steel, tribochemical reactions occur which control the coefficient of friction. The presence of hydrophilic groups plays an important role in the low friction in a water environment. The presence of $\mathrm{Fe}-\mathrm{C}$ bonding was shown on the DLC wear track $[52,57]$, as well as $\mathrm{Fe}-\mathrm{O}, \mathrm{C}-\mathrm{O}, \mathrm{C}=\mathrm{O}$, and $\mathrm{O}-\mathrm{C}=\mathrm{O}$ bonding, relating to tribochemical reactions of the DLC coating with steel, and with the environment. These reactions control the coefficient of friction, and not the hydrogen content on the DLC coating. Reaction mechanisms for the oxidation of a DLC coating in 
a humid environment, and the reaction of Fe with a DLC coating in a humid environment, have been suggested [51,52].

\section{Conclusions}

For a DLC coating under water lubrication, the adhesive component of friction is controlled by tribochemical reactions. The deposition process, test environment, test conditions, and counterface will all affect the tribochemistry. The literature has shown how oxidation of the DLC coating surface occurs in water [56]. Against steel, a high and high variance coefficient of friction was observed as a result of tribochemical reactions between surfaces [51]. Against more inert counterface materials such as silicon nitride, lower friction was observed. In dry nitrogen, friction was observed to increase as a function of relative humidity-where higher proportions of $\mathrm{C}-\mathrm{O}$, $\mathrm{C}=\mathrm{O}$, and $\mathrm{Fe}-\mathrm{O}$ bonding was observed as humidity increased. The literature suggests that ta- $C$ coatings show the lowest friction under water lubricationresultant of a hydrophilic surface layer providing lubricious properties.

Interfacial sliding of a transfer layer will yield a low and steady coefficient of friction, where the frictional response is dependent on the adhesive interactions between surfaces. When shear of the transfer layer occurs, a higher and more varied coefficient of friction may be observed and this relates to the accumulated energy required to shear the loose debris. The motions of the third body then control the frictional response. The third-body dynamics are dependent on the test parameters (load and sliding velocity), test environment, temperature, and material pairing, as well as the deposition of the DLC coating.

In order to have confidence in the use of a DLC coating in a water-based application, further work is required to understand the range of system parameters for which a low and stable coefficient of friction is observed. The stability of a transfer layer on the surface of the counterface is critical to maintaining this low friction behaviour. The influence of a steel counterface has been discussed, but the sensitivity of the friction to the counterface material must be reiterated.

\section{Acknowledgements}

We acknowledge the support of the National Centre for Advanced Tribology (nCATS) and EPSRC grant EP/F034296/1. D. Sutton acknowledges support through a Rolls-Royce sponsored $\mathrm{PhD}$ studentship at the University of Southampton.

Open Access: This article is distributed under the terms of the Creative Commons Attribution License which permits any use, distribution, and reproduction in any medium, provided the original author(s) and source are credited.

\section{References}

[1] Ferrari A C. Non-destructive characterisation of carbon films. In Tribology of Diamond-Like Carbon Films. Donnet C, Erdemir A, Ed. Berlin: Springer, 2008: 25-82.

[2] Ferrari A C, Robertson J. Raman spectroscopy of amorphous, nanostructured, diamond-like carbon, and nanodiamond. Philos T R Soc A 362(1824): 2477-2512 (2004)

[3] Robertson J. Diamond-like amorphous carbon. Mater Sci Eng R Rep 37(4-6): 129-281 (2002)

[4] Jacob W, Moller W. On the structure of thin hydrocarbon films. Appl Phys Lett 63(13): 1771-1773 (1993)

[5] Ban M, Hasegawa T, Fujii S, Fujioka J. Stress and structural properties of diamond-like carbon films deposited by electron beam excited plasma CVD. Diam Relat Mater 12(1): 47-56 (2003)

[6] Oka Y, Kirinuki M, Nishimura Y, Azuma K, Fujiwara E, Yatsuzuka M. Measurement of residual stress in DLC films prepared by plasma-based ion implantation and deposition. Surf Coat Tech 186(1-2): 141-145 (2004)

[7] Kumar S, Sarangi D, Dixit P N, Panwar O S, Bhattacharyya R. Diamond-like carbon films with extremely low stress. Thin Solid Films 346(1-2): 130-137 (1999)

[8] Yamada H, Tsuji O. Characteristics of diamondlike carbon thin films prepared by rf plasma pulsed deposition methodEffect of annealing temperature. J Ceram Soc Jpn 105(1): 62-67 (1997)

[9] Sánchez-López J C, Fernández A. Doping and alloying effects on DLC coatings. In Tribology of Diamond-Like Carbon Films. Donnet C, Erdemir A, Ed. Berlin: Springer, 2008: 311-338.

[10] Love C A, Cook R B, Harvey P A, Wood R J K. Diamond like carbon coatings for potential application in biological implants-A review. Tribol Int 63: 141-150 (2012)

[11] Lemoine P, Quinn J P, Maguire P D, McLaughlin J A. Mechanical characterisation and properties of DLC films. 
In Tribology of Diamond-Like Carbon Films. Donnet C, Erdemir A, Ed. Berlin: Springer, 2008: 83-101.

[12] Bull S J. Tribology of carbon coatings-DLC, diamond and beyond. Diam Relat Mater 4(5-6): 827-836 (1995)

[13] Donnet C. Recent progress on the tribology of doped diamond-like and carbon alloy coatings: A review. Surf Coat Tech 100(1-3): 180-186 (1998)

[14] Donnet C, Erdemir A. Tribology of Diamond-Like Carbon Films. Berlin: Springer, 2008.

[15] Erdemir A, Donnet C. Tribology of diamond-like carbon films: Recent progress and future prospects. J Phys D Appl Phys 39(18): R311-R327 (2006)

[16] Grill A. Tribology of diamondlike carbon and related materials: An updated review. Surf Coat Tech 94-95(1-3): 507-513 (1997)

[17] Semenov A P, Khrushchov M M. Influence of environment and temperature on tribological behavior of diamond and diamond-like coatings. J Frict Wear 31(2): 142-158 (2010)

[18] Sutton D C, Limbert G, Burdett B, Wood R J K. Interpreting the effects of interfacial chemistry on the tribology of diamond-like carbon coatings against steel in distilled water. Wear 302: 918-928 (2013)

[19] Fontaine J, Donnet C, Erdemir A. Fundamentals of the tribology of DLC coatings. In Tribology of Diamond-Like Carbon Films. Berlin: Springer, 2008: 139-154.

[20] Erdemir A, Nichols F A, Pan X Z. Friction and wear performance of ion-beam-deposited diamond-like carbon-films on steel substrates. Diam Relat Mater 3(1-2): 119-125 (1994)

[21] Voevodin A A, Phelps A W, Zabinski J S, Donley M S. Friction induced phase transformation of pulsed laser deposited diamond-like carbon. Diam Relat Mater 5(11): 1264-1269 (1996)

[22] Scharf T W, Singer I L. Monitoring transfer films and friction instabilities with in situ Raman tribometry. Tribol Lett 14(1): 3-8 (2003)

[23] Low M B J. Effect of the transfer film on the friction and wear of dry bearing materials for a power-plant application. Wear 52(2): 347-363 (1979)

[24] Erdemir A. Friction and wear of diamond and diamond-like carbon films. Proc IMechE, Part J: J Eng Tribol 216(J6): 387-400 (2002)

[25] Erdemir A. The role of hydrogen in tribological properties of diamond-like carbon films. Surf Coat Tech 146: 292-297 (2001)

[26] Erdemir A. Genesis of superlow friction and wear in diamondlike carbon films. Tribol Int 37(11-12): 1005-1012 (2004)

[27] Andersson J, Erck R A, Erdemir A. Friction of diamondlike carbon films in different atmospheres. Wear 254(11): 1070-1075 (2003)

[28] Ronkainen H, Holmberg K. Environmental and thermal effects on the tribological performance of DLC coatings.
In Tribology of Diamond-Like Carbon Films. Donnet C, Erdemir A, Ed. Berlin: Springer, 2008: 155-200.

[29] Meunier C, Alers P, Marot L, Stauffer J, Randall N, Mikhailov S. Friction properties of ta-C and a-C:H coatings under high vacuum. Surf Coat Tech 200(5-6): 1976-1981 (2005)

[30] Enke K, Dimigen H, Hubsch H. Frictional-properties of diamond-like carbon layers. Appl Phys Lett 36(4): 291-292 (1980)

[31] Voevodin A A, Donley M S, Zabinski J S, Bultman J E. Mechanical and tribological properties of diamond-like carbon coatings prepared by pulsed laser deposition. Surf Coat Tech 76-77(1-3): 534-539 (1995)

[32] Fontaine J, Le Mogne T, Loubet J L, Belin M. Achieving superlow friction with hydrogenated amorphous carbon: Some key requirements. Thin Solid Films 482(1-2): 99-108 (2005)

[33] Heimberg J A, Wahl K J, Singer I L, Erdemir A. Superlow friction behavior of diamond-like carbon coatings: Time and speed effects. Appl Phys Lett 78(17): 2449-2451 (2001)

[34] Oguri K, Arai T. Tribological properties and characterization of diamond-like carbon coatings with silicon prepared by plasma-assisted chemical vapor-deposition. Surf Coat Tech 47(1-3): 710-721 (1991)

[35] Gilmore R, Hauert R. Comparative study of the tribological moisture sensitivity of Si-free and Si-containing diamondlike carbon films. Surf Coat Tech 133: 437-442 (2000)

[36] Rubio-Roy M, Corbella C, Bertran E, Portal S, Polo M C, Pascual E, Andújar J L. Effects of environmental conditions on fluorinated diamond-like carbon tribology. Diam Relat Mater 18(5-8): 923-926 (2009)

[37] Bhushan B, Gupta B K. Friction and wear of ion-implanted diamond-like carbon and fullerene films for thin-film rigid disks. J Appl Phys 75(10): 6156-6158 (1994)

[38] Erdemir A, Bindal C, Fenske G R, Zuiker C, Wilber P. Characterization of transfer layers forming on surfaces sliding against diamond-like carbon. Surf Coat Tech 86-87(1-3): 692-697 (1996)

[39] Jiang J R, Arnell R D. On the running-in behaviour of diamond-like carbon coatings under the ball-on-disk contact geometry. Wear 217(2): 190-199 (1998)

[40] Miyoshi K. Studies of mechanochemical interactions in the tribological behavior of materials. Surf Coat Tech 43-44(1-3): 799-812 (1990)

[41] Ronkainen H, Varjus S, Holmberg K. Tribological performance of different DLC coatings in water-lubricated conditions. Wear 249(3-4): 267-271 (2001)

[42] Singer I L, Dvorak S D, Wahl K J, Scharf T W. Role of third bodies in friction and wear of protective coatings. $J$ Vac Sci Technol A 21(5): S232-S240 (2003)

[43] Scharf T W, Singer I L. Third bodies and tribochemistry of DLC coatings. In Tribology of Diamond-Like Carbon Films. 
Donnet C, Erdemir A, Ed. Berlin: Springer, 2008: 201-236.

[44] Scharf T W, Singer I L. Role of the transfer film on the friction and wear of metal carbide reinforced amorphous carbon coatings during run-in. Tribol Lett 36(1): 43-53 (2009)

[45] Hsu S M, Klaus E E, Cheng H S. A mechano-chemical descriptive model for wear under mixed lubrication conditions. Wear 128(3): 307-323 (1988)

[46] Andersson J, Erck R A, Erdemir A. Frictional behavior of diamondlike carbon films in vacuum and under varying water vapor pressure. Surf Coat Tech 163: 535-540 (2003)

[47] Uchidate M, Liu H, Iwabuchi A, Yamamoto K. Effects of water environment on tribological properties of DLC rubbed against stainless steel. Wear 263: 1335-1340 (2007)

[48] Ding Q, Wang L P, Wang Y X, Wang S C, Hu L T, Xue Q J. Improved tribological behavior of DLC films under water lubrication by surface texturing. Tribol Lett 41(2): 439-449 (2011)

[49] Tokoro M, Aiyama Y, Masuko M, Suzuki A, Ito H, Yamamoto K. Improvement of tribological characteristics under water lubrication of DLC-coatings by surface polishing. Wear 267(12): 2167-2172 (2009)

[50] Park S J, Lee K R, Ko D H. Tribochemical reaction of hydrogenated diamond-like carbon films: a clue to understand the environmental dependence. Tribol Int 37(11-12): 913-921 (2004)

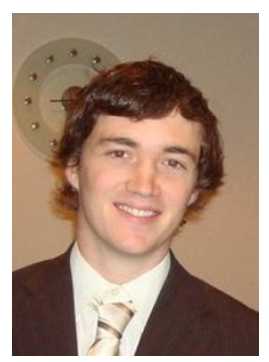

D. C. SUTTON. He received his MMath degree in Mathematics from the University of Exeter, UK, in 2010. Currently, he is a PhD candidate at the National Centre for Advanced

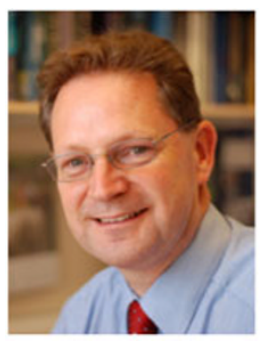

R. J. K. WOOD. He is a professor and director of the National Centre for Advanced Tribology at Southampton (nCATS), within the Faculty of Engineering and the Environment at the University of Southampton, and has 25 years research experience in the field of tribology and surface engineering. He has spent several years at BP Research researching into erosion and corrosion
[51] Li H X, Xu T, Wang C B, Chen J M, Zhou H D, Liu H W. Friction-induced physical and chemical interactions among diamond-like carbon film, steel ball and water and/or oxygen molecules. Diam Relat Mater 15(9): 1228-1234 (2006)

[52] Li H, Xu T, Wang C, Chen J, Zhou H, Liu H. Tribochemical effects on the friction and wear behaviors of diamond-like carbon film under high relative humidity condition. Tribol Lett 19(3): 231-238 (2005)

[53] Liu Y, Erdemir A, Meletis E I. A study of the wear mechanism of diamond-like carbon films. Surf Coat Tech 82(1-2): 48-56 (1996)

[54] Hutchings I M. Tribology: Friction and Wear of Engineering Materials. London: Edward Arnold, 1992.

[55] Goto Y. The effect of squeezing on the phase transformation and magnetic properties of $\gamma-\mathrm{Fe}_{2} \mathrm{O}_{3}$. J Appl Phys Jpn 3: 739-744 (1964)

[56] Wu X, Ohana T, Tanaka A, Kubo T, Nanao H, Minami I, Mori S. Tribochemical investigation of DLC coating in water using stable isotopic tracers. Appl Surf Sci 254(11): 3397-3402 (2008)

[57] Fukui H, Irie M, Utsumi Y, Oda K, Ohara H. An investigation of the wear track on DLC (a-C : H) film by time-of-flight secondary ion mass spectroscopy. Surf Coat Tech 146: 378-383 (2001)

Tribology (nCATS) at the University of Southampton. His research concerns predictive modelling of the wear of diamond-like carbon coatings sliding against steel in a deionised water environment.

resistant coatings but returned to Southampton in 1993 to re-establish surface engineering/tribology research. His group was awarded a EPSRC S\&I award in $2008(£ 10 \mathrm{M})$ to create the National Centre for Advanced Tribology at Southampton (nCATS) and was awarded a further $£ 3 \mathrm{M}$ for research into Green Tribology under a platform Grant from EPSRC. The Centre has 9 academics, 12 postdoctoral research fellows and 20 research students. 